This item was submitted to Loughborough's Research Repository by the author.

Items in Figshare are protected by copyright, with all rights reserved, unless otherwise indicated.

\title{
A mild Lewis acid mediated epoxy-ester to bicyclic ortho ester rearrangement
}

\section{PLEASE CITE THE PUBLISHED VERSION}

http://dx.doi.org/10.1039/c3cc44364g

\section{PUBLISHER}

(c) Royal Society of Chemistry

\section{VERSION}

AM (Accepted Manuscript)

\section{PUBLISHER STATEMENT}

This work is made available according to the conditions of the Creative Commons Attribution-NonCommercialNoDerivatives 4.0 International (CC BY-NC-ND 4.0) licence. Full details of this licence are available at: https://creativecommons.org/licenses/by-nc-nd/4.0/

\section{LICENCE}

CC BY-NC-ND 4.0

\section{REPOSITORY RECORD}

Ahmed, Awais, Steven D.R. Christie, Mark R.J. Elsegood, and Gareth J. Pritchard. 2019. "A Mild Lewis Acid Mediated Epoxy-ester to Bicyclic Ortho Ester Rearrangement”. figshare. https://hdl.handle.net/2134/15919. 


\title{
A Mild Lewis Acid Mediated Epoxy-Ester to Bicyclic Ortho Ester Rearrangement
}

\author{
Awais Ahmed, Steven D. R. Christie, ${ }^{a}$ Mark R. J. Elsegood and Gareth J. Pritchard ${ }^{* b}$ \\ Received (in $X X X, X X X)$ Xth $X X X X X X X X X 20 X X$, Accepted Xth $X X X X X X X X X 20 X X$ \\ DOI: 10.1039/b000000x
}

\begin{abstract}
A high yielding rearrangement of epoxy-esters, under Lewis acid conditions, to give bicyclic ortho esters is reported.
\end{abstract}

We have an interest in the development of new methods to prepare heterocyclic systems; including stoichiometric 10 organometallics, ${ }^{1}$ palladium mediated reactions, ${ }^{2}$ biomimetic methods, ${ }^{3}$ condensation of reactive electrophilic systems. ${ }^{4} \mathrm{We}$ now wish to report a new route to methoxy substituted dioxabicyclo[3.2.1]octane systems using a epoxy-ester to ortho ester rearrangement.

15 The rearrangement of epoxy-esters to ortho esters is a well established reaction. ${ }^{5}$ It has found applications in the protection of carboxylic acids, ${ }^{6}$ in total synthesis of natural products, ${ }^{7}$ and also in numerous elegant biomimetic chemistry. ${ }^{8}$ The majority of the reports focused on the formation of a trioxabicyclic ortho 20 ester where the epoxide of the precursor is in the alkoxide part of the ester (Type I, Scheme 1). Our curiosity led us to investigate the formation of a lesser-known configuration of bicyclic ortho ester starting from a precursor where the epoxide is linked to the carbonyl of the ester (Type II, Scheme 1).<smiles>[3H]C(=O)OCC[C@@H]1C[C@H]1I</smiles>

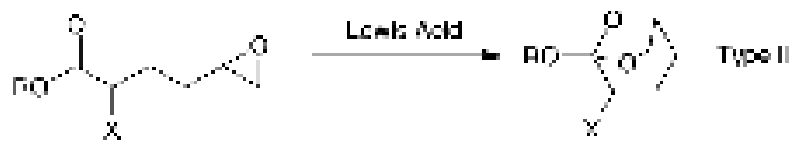

$$
\text { i1: } x \text {-colie }
$$

${ }_{25}$ Scheme 1 Epoxy-ester to ortho ester rearrangement.

To our knowledge there have been only two reports of this type of reaction, both being in the field of diterpene chemistry (Scheme 2). ${ }^{9,10}$ Urones has reported the unexpected formation of 30 such an ortho ester during a Sharpless asymmetric epoxidation of a diterpene. ${ }^{9}$ The chemistry was further used in the semisynthesis of bioactive drimanes, pereniporin $\mathrm{B}$ and warburganal, but no follow up on the ortho ester chemistry. ${ }^{10} \mathrm{We}$ believe this reaction warrants further exploration since ortho ester remain an under 35 exploited functional group in organic chemistry, thus giving access to unusual compounds and opens up the development of new chemical space. Herein we report our preliminary studies.

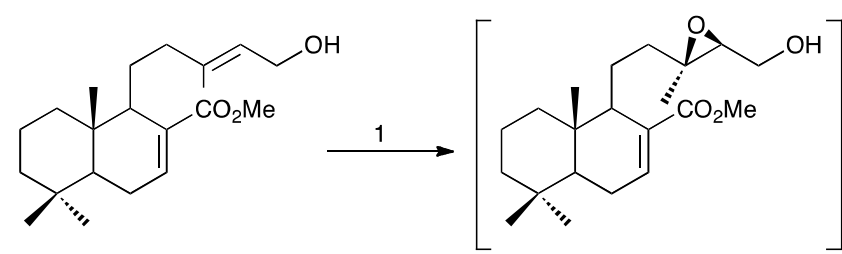

1) $\mathrm{Ti}(i-\mathrm{PrO})_{4}, \mathrm{~L}-(+)-\mathrm{DET}, t-\mathrm{BuOOH}, \mathrm{DCM}$<smiles>CO[C@]12O[C@](C)(CCC1C1=CCC3C(C)(C)CCC[C@]3(C)[C@H]1CO)O2</smiles>

Scheme 2 Formation of ortho ester in an asymmetric epoxidation.

40 Our initial ortho ester target is the methoxy substituted dioxabicyclo[3.2.1] octane (1). It was chosen because the bridged 5,6-membered ring system was expected to be the both kinetically and thermodynamically stable, thus improving our prospect of isolating the desired bicyclic ortho ester. The use of 45 alkylated dimethyl malonate derivatives as starting materials allowed quick access to the epoxy ester precursors. Also the desymmetrization of the malonic ester center during the reaction would give additional insights into the reaction (Scheme 1, Type II, $\mathrm{X}=\mathrm{CO}_{2} \mathrm{Me}$ ). The required epoxy ester (2) was prepared by 50 alkylation of dimethyl malonate with 4-bromo-1-butene and subsequent epoxidation with mCPBA in good over all yield (Scheme 3).

With the required epoxy ester in hand, we attempted the Lewis acid catalysed rearrangement by straightforward treatment with ${ }_{55} \mathrm{ZnBr}_{2}$ in DCM. After 8 hours at room temperature, it was gratifying to isolate the targeted ortho ester product as two separable diastereoisomers in a good combined yield of $80 \%$ (Scheme 4). The relative stereochemistry of diastereoisomers (1a)

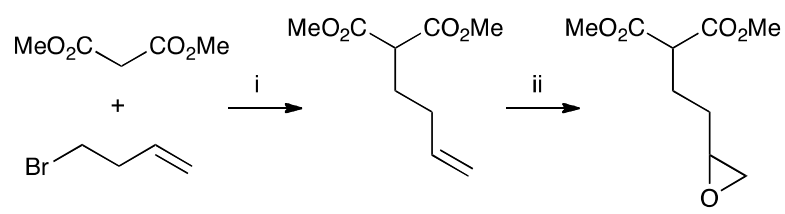

i) $\mathrm{NaH}, \mathrm{DMF}, 0^{\circ} \mathrm{C}, 12 \mathrm{hrs}, 80 \%$.

(2)

Scheme 3 Preparation of the epoxy ester. 


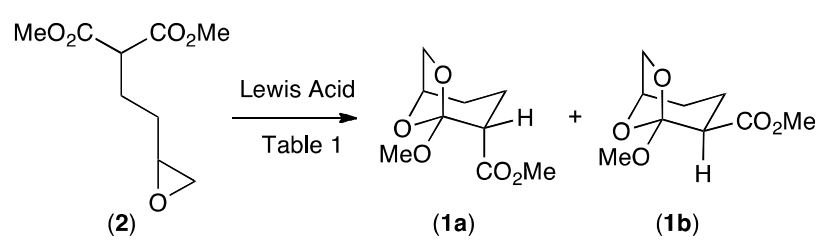

Scheme 4 Trial Lewis acid catalysed rearrangement reaction.

and (1b) where confirmed by nOe experiments and single crystal $\mathrm{X}$-ray structures.

This successful initial result was followed up by possible optimisation under a range of reaction conditions (Table 1). The 5 same substrate (2) was reacted using a limited range of Lewis Acids, solvents and conditions. The most successful Lewis acids were found to be $\mathrm{ZnBr}_{2}$ and $\mathrm{Yb}(\mathrm{OTf})_{3}$. Some variations in the diastereoselectivity was seen with $\mathrm{ZnBr}_{2}$ depending on the reaction conditions while $\mathrm{Yb}(\mathrm{OTf})_{3}$ giving essentially one 10 diastereoisomer. The chlorinated solvents DCM and DCE appear to be best solvents for this reaction and it typically ran smoothly at room temperature over a period 8 hours.

\begin{tabular}{|c|c|c|c|c|c|}
\hline $\begin{array}{c}\text { Lewis } \\
\text { Acid }\end{array}$ & Solvent & Equiv. & Temp. & Time & $\begin{array}{c}\text { Yield \% } \\
(\mathbf{1 a}: 1 \mathbf{b})\end{array}$ \\
\hline $\mathrm{ZnBr}_{2}$ & DCM & 1.0 & RT & $8 \mathrm{~h}$ & $80(17: 63)$ \\
\hline $\mathrm{ZnBr}_{2}$ & DCM & 0.1 & Reflux & $12 \mathrm{~h}$ & $80(30: 50)$ \\
\hline $\mathrm{ZnBr}_{2}$ & DCE & 0.1 & $50^{\circ} \mathrm{C}$ & $12 \mathrm{~h}$ & $90(30: 60)$ \\
\hline $\mathrm{ZnBr}_{2}$ & DCE & 1.0 & RT & $8 \mathrm{~h}$ & $90(30: 60)$ \\
\hline $\mathrm{ZnBr}_{2}$ & Toluene & 0.1 & $40^{\circ} \mathrm{C}$ & $18 \mathrm{~h}$ & $58(24: 34)$ \\
\hline $\mathrm{ZnBr}_{2}$ & THF & 1.0 & $60^{\circ} \mathrm{C}$ & $6 \mathrm{~h}$ & - \\
\hline $\mathrm{MgBr}_{2}$ & DCM & 1.0 & RT & $10 \mathrm{~h}$ & - \\
\hline $\mathrm{BF}_{3} \cdot \mathrm{OEt}$ & DCM & 0.1 & RT & $1 \mathrm{~h}$ & - \\
\hline $\mathrm{Sc}(\mathrm{OTf})_{3}$ & DCM & 0.01 & Reflux & $20 \mathrm{~min}$ & $30(0: 30)$ \\
\hline $\mathrm{Yb}(\mathrm{OTf})_{3}$ & DCM & 0.1 & Reflux & $8 \mathrm{~h}$ & $75(0: 75)$ \\
\hline
\end{tabular}

Table 1 Results of Lewis acids used and reaction conditions.

The scope of this ortho ester formation reaction was then explored using a range of epoxy ester substrates. The first variation was the introduction of an additional alkyl group to the malonic ester. This would examine the effect of steric bulk at this 20 position and allow the incorporation of a quaternary centre into the molecule. It is also interesting to note that the quaternary centre is adjacent the quaternary centre of the ortho ester, since the generation of vicinal quaternary carbon centers, always a challenge for organic synthesis. The substrates (3-5) were readily ${ }_{25}$ prepared by standard alkylation chemistry, as outlined above (Scheme 3). Yields for all three examples, $\mathrm{Me}, \mathrm{Ph}, \mathrm{CH}_{2} \mathrm{Ph},(\mathbf{6 - 8})$ ranged from reasonable to good (Scheme 5). The stereoselectivity of the reactions saw no major changes. This observation is consistent with our proposed reaction mechanism with Lewis acid 30 coordination directing the orientation of the product's ester group instead of simply a result of steric effect
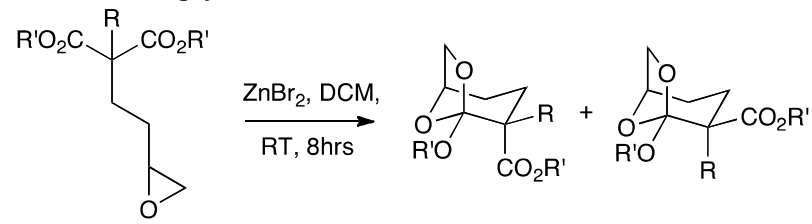
(3) $\mathrm{R}=\mathrm{Me}, \mathrm{R}^{\prime}=\mathrm{Me}$
(6a) $17 \%$
(7a) $15 \%$
(4) $\mathrm{R}=\mathrm{CH}_{2} \mathrm{Ph}, \mathrm{R}^{\prime}=\mathrm{Me}$
(8a) $9 \%$
(6b) $63 \%$
7b) $63 \%$
(8b) $30 \%$

Scheme 5 Introduction of a substituent and the malonate centre.
The next extension to the work was to explore the possibility of introducing a substituent on the epoxide. To this end gemdisubstituted expoxides (9-10) were prepared in order to examine 35 the additional alkyl group's influence on cyclisation under Lewis acid conditions. It was gratifying to find that both examples worked well giving products (11-12) combined yields of $77 \%$ and $90 \%$ respectively, in a rough ration of $1: 2$, showing a substituient at this position has little impact on the reaction (Scheme 6).

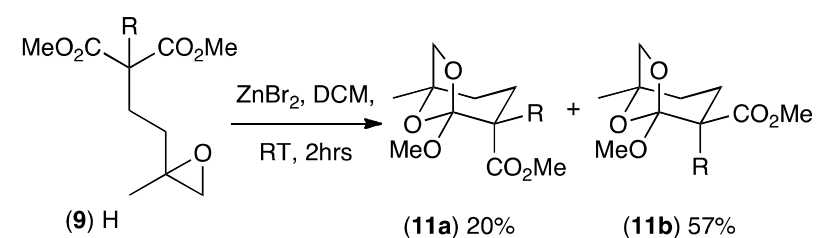

(10) $\mathrm{CH}_{2} \mathrm{Ph}$

$(11 a)$

Scheme 6 Reactions using a substituted epoxide starting material.

40 Following the above positive results, we turned our attention to 1,2-disubstituted epoxides (13) and (14) analogous to investigation by Sum and Weiler into the stereochemical outcome of the Lewis acid catalysed isomerisation of epoxides to give ketals. ${ }^{11}$ They have shown the epoxide ring opening was 45 stereospecific by using cis and trans epoxides. We therefore undertook similar work to see if the rearrangement of epoxy-ester to ortho ester reaction was also stereospecific. The epoxides (13) and (14) were readily prepared by alkylation, subsequent epoxidation from respective $Z$ and $E$ alkenes (Scheme 7).

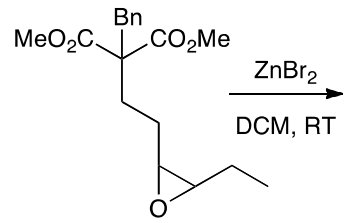

(13)

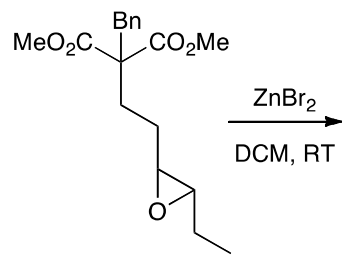

(14)

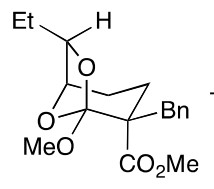

(15a) $19 \%$ *
( $2: 1$ inseparable mixture of $15 a$ and $15 b)$

Scheme 7 Reactions using substituted cis and trans epoxides.

50 The results are inline with the findings of Sum and Weiler ${ }^{11}$ that the reaction occurs with nucleophilic ring opening of the epoxide by the oxygen lone pair leading to inversion of stereochemistry at that centre to give ortho ester (15a-b) and (16a-b). The mechanism and stereoselectivity of the reaction can 55 be rationalised as below (Scheme 8). The variation in diastereoselectivity with the Lewis acid (Table 1) and the evidenced of inversion of epoxide (Scheme 7) suggest to us there is some coordination, or pre-organisation, between the epoxide and non-reacting ester before ring opening of the epoxide. Simple 60 models suggest that a 7-membered chelate would still allow for backside attack on the epoxide by the non-chelated ester. Further experimental work and modelling on this aspect is ongoing. 


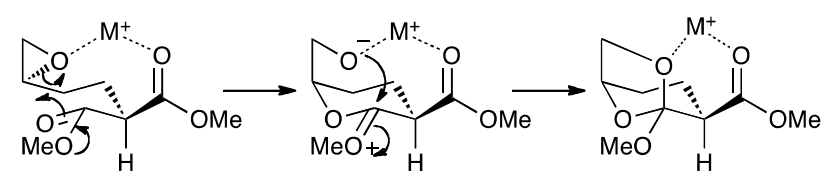

Scheme 8 Mechanism and explanation of stereoselectivity.

Another aspect of the reaction we wish to explore is its chemoselectivity. There have been numerous reports on the rearrangement of epoxy-ketones into dioxabicyclo[3.2.1]octanes which is related to our ortho ester rearrangement chemistry. 11 5 The rearrangement precursor (17) would serve as the ideal starting material to determine whether the ester carbonyl or the ketone carbonyl would be more reactive under the Lewis acid rearrangement reaction condition. It was prepared as a pair of inseparable diastereomers $(\mathbf{1 7 a}-\mathbf{b})$ by alkylation of ethyl 10 acetoacetate with 4-bromo-1-butene, followed by epoxidation with mCPBA. Reaction between the ester and the epoxide will give the ortho ester, otherwise reaction between the ketone and the epoxide will give the ketal product. After treatment of (17a-b) with $\mathrm{ZnBr}_{2}$ in $\mathrm{DCM}$, only two out of the four potential products 15 were exclusively formed (Scheme 9). The two separable products were isolated with a combined yield of $80 \%$ in a $1: 1$ ratio. The NMR studies suggested diastereoisomers (18a) and (18b) were formed which was confirmed by $\mathrm{LiAlH}_{4}$ reduction giving the ketals (19a) and (19b) respectively in preference to their ortho 20 esters counterparts. To date no kinetic studies have been carried out to see if the ortho ester is formed initially, however when the ketals (18a) and (18b) are re-subjected to the reaction conditions no change is observed. The result was somewhat unexpected since the ester group is marginally more nucleophilic due to ${ }_{25}$ electron donating effect of the alkoxy group. However it may be

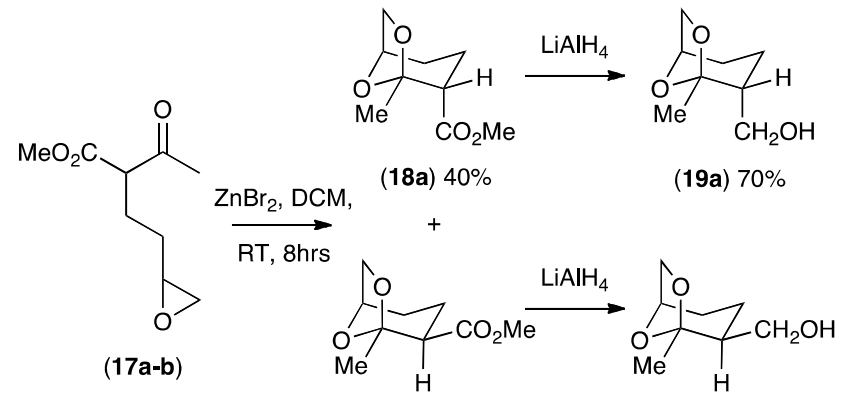

(18b) $40 \%$

(19b) $75 \%$

Scheme 9 Reactions using an acetoacetate derived epoxide.

the case that the Lewis acid is coordinating strongly to the ester group thus reducing its nucleophilicity.

\section{Conclusions}

${ }_{30} \mathrm{We}$ have thus established a high yielding versatile route to methoxy substituted dioxabicyclo[3.2.1] octane, we believe this is a useful addition to the field of ortho esters synthesis. The chemistry also is an interesting example of desymmetrisation of the malonic ester center during the reaction that could be proved 35 useful. We are currently looking at expanding the reaction, by controlling the stereochemistry, cascade reactions and applications in synthesis.

\section{Notes and references}

${ }^{a}$ Department of Chemistry, University of Loughborough, Loughborough, 40 Leicestershire, LE11 3TU, UK. Fax: +44(0)1509 22395; Tel; +44(0)1509 222587; E-mail: S.D.Christie@lboro.ac.uk

${ }^{b}$ Department of Chemistry, University of Loughborough, Loughborough, Leicestershire, LE11 3TU, UK. Fax: +44(0)1509 22395; Tel; +44(0)1509 222586; E-mail: G.J.Pritchard@lboro.ac.uk

$45 \dagger$ Electronic Supplementary Information (ESI) available: Experimental procedures, analytical data, crystal structure diagarams for 1a, 1b, 15b, and 16b, and copies of NMR spectra are available in the ESI. See DOI: $10.1039 / \mathrm{b} 000000 \mathrm{x} /$

1) S. D. R. Christie, R. J. Davoile, M. R. J. Elsegood, R. Fryatt, R. C. F.

50 Jones and G. J. Pritchard, Chem. Commun., 2004, 2474; S. D. R. Christie, R. J. Davoile and R. C. F. Jones, Org. Bio. Chem., 2006, 4, 2683; S. D. R. Christie, J. Cummins, M. R. J. Elsegood and G. Dawson, Synlett, 2010, 257; E. A. Ellart, M. R. J. Elsegood, S. D. R. Christie and G. J. Pritchard, Chem. Commun., 2009, 7339; S. D. R.

55 Christie, J. C. Cummins, M. R. J. Elsegood, G. Dawson, Synthesis, 2009, 257.

2) W. R. Bowman, J. E. Lyon and G. J. Pritchard, Synlett, 2008, 2169; W. R. Bowman, J. E. Lyon and G. J. Pritchard, ARKIVOC, 2012, part vii, 210; S. D. R. Christie, A. D. Warrington, C. J. Lunniss, Synthesis, 2009, 148. R. J. Davoile, D. T. Rutherford, S. D. R. Christie, Tetrahedron Lett., 2000, 41, 1255.

3) For example see:- N. R. Irlapati, J. E. Baldwin, R. M. Adlington, G. J. Pritchard and A. R. Cowley, Tetrahedron, 2006, 62, 4603; R. M. Adlington, J. E. Baldwin, A. V. W. Mayweg and G. J. Pritchard, Org.

65 Lett., 2002, 4, 3009; R. M. Adlington, J. E. Baldwin, A. J. Williams and D. J. Watkin, Org. Lett., 1999, 1, 1937; N. R. Irlapati, J. E. Baldwin, R. M. Adlington and G. J. Pritchard, Org. Lett., 2003, 5, 2351.

4) For examples see:- M. F. A. Adamo, R. M. Adlington, J. E. Baldwin, 70 G. J. Pritchard and R. E. Rathmell, Tetrahedron, 2003, 59, 2197; J. E. Baldwin, A. M. Fryer and G. J. Pritchard, Bioorg. Med. Chem. Lett., 2000, 10, 309; R. M. Adlington, J. E. Baldwin, D. Catterick and G. J. Pritchard, Chem. Commun., 1997, 1757.

5) H. Meerwein, Angew. Chem., 1955, 67, 374; L. I. Kas'yan, I. N. Tarabara and A. O. Kas'yan, Russ. J. Org. Chem., 2004, 40, 1227.

6) P. Wipf, T. Tsuchimoto, H. Takahashi, Pure Appl. Chem., 1999, 71, 415; P. Wipf, W. Xu, H. Kim, H. Takahashi, Tetrahedron, 1997, 53, 16575; P. Wipf and D. C. Aslan, J. Org. Chem., 2001, 66, 337.

7) J.-L. Giner, W. V. Ferris Jr. and J. J. Mullins, J. Org. Chem., 2002, $80 \quad 67,4856$

8) J.-L. Giner and J. A. Faraldos, J. Org. Chem., 2002, 67, 2717.

9) J. G. Urones, I. S. Marcos, P. Basabe, M. J. Sexmero, D. Diez, N. M. Garrido and J. E. S. Prieto, Tetrahedron, 1990, 46, 2495.

10) J. G. Urones, I. S. Marcos, B. G. Pérez, D. Díez, A. M. Lithgow, P. M. Gómez, P. Basabe and N. M. Garrido, Tetrahedron, 1994, 50, 10995.

11) P. E. Sum and L. Weiler, Can. J. Chem., 1979, 57, 1475. 